\title{
Use of geogrid in the construction of railroads
}

\author{
Braja M. Das ${ }^{1}$
}

Received: 13 June 2016/Accepted: 16 June 2016/Published online: 28 June 2016

(C) Springer International Publishing Switzerland 2016

\begin{abstract}
Over the last three decades geogrid has been used as a reinforcement in the construction of several earthretaining and earth-supported structures. In more recent times it has been used as reinforcement of railroad beds to improve its performance and structural integrity. A review of several published field and large-scale laboratory test results relating to the reinforcing ability of geogrids is presented. Also included are a number of case histories from several countries where layer(s) of geogrid were used in ballast and sub-ballast layers and on soft subgrade to reduce track settlement and, hence, the frequency of maintenance.
\end{abstract}

Keywords Ballast - Bearing capacity improvement . Geogrid · Maintenance reduction - Reinforcement . Subgrade

\section{Introduction}

A geogrid is defined as a polymeric (i.e., geosynthetic) material consisting of connected parallel sets of tensile ribs with apertures of sufficient size to allow strike-through of surrounding soil, stone, or other geotechnical material. Their primary functions are reinforcement and separation. Reinforcement refers to the mechanism(s) by which the engineering properties of the composite soil/aggregate are mechanically improved. Separation refers to the physical isolation of dissimilar materials-say, ballast and subballast or sub-ballast and subgrade- such that they do not

Braja M. Das

brajamdas@gmail.com

1 California State University Sacramento, Henderson, NV, USA commingle. Netlon Ltd. of the UK was the first producer of geogrids. In 1982 the Tensar Corporation (presently Tensar International [18]) introduced geogrids in the US.

Historically speaking, in the 1950's Dr. Brian Mercer (1927-1998) developed the Netlon ${ }^{\circledR}$ process in which plastics are extruded into a net-like process in one stage. $\mathrm{He}$ founded Netlon Ltd. in the UK in 1959 to manufacture the product. Based on Dr. Mercer's further innovative research and development work on extruded net technology, some polymer straps and strips were formed into grid-like products during the 1970's, but the first integral geogrids were developed in the late 1970's and first employed in various applications in the early 1980's. In the early stages of the development of geogrid several universities in the UK, namely Leeds, Nottingham, Oxford, Sheffield and Strathclyde, were heavily involved in a comprehensive program of research that examined the polymer technology.

The initial extruded geogrids developed by Netlon Ltd. were of two types-biaxial and uniaxial (Fig. 1). They were formed using a thick sheet of polyethylene or polypropylene that was punched and drawn to create apertures and to enhance engineering properties of the resulting ribs and nodes. Original uniaxial extruded geogrids were manufactured by stretching a punched sheet of high-density polyethylene in one direction under carefully controlled conditions. This process aligned the polymer's long-chain molecules in the direction of draw and resulted in a product with high one-directional tensile strength and modulus. Biaxial geogrids were manufactured by stretching the punched sheet of polypropylene in two orthogonal directions. This process resulted in a product with high tensile strength and modulus in two perpendicular directions. The resulting grid apertures were either square or rectangular.

At the present time there are several types of geogrids commercially available in different countries. In addition to 
extruded geogrids, woven and welded geogrids are also available commercially. Woven geogrids are manufactured by grouping polymeric-usually polyester or polypropylene-and weaving them into a mesh pattern that is then coated with a polymeric lacquer. Welded geogrids are manufactured by fusing junctions of polymeric strips. Extruded geogrids have shown good performance when compared to other types when used in pavement reinforcement applications. The commercial uniaxial and biaxial geogrids currently available for soil reinforcement have nominal rib thicknesses of about $0.5-1.5 \mathrm{~mm}$ and junctions of about $2.5-5 \mathrm{~mm}$. The grids used for soil reinforcement usually have apertures that are rectangular or elliptical in shape. The dimensions of the apertures vary from about $25-150 \mathrm{~mm}$. Geogrids are generally manufactured so that the open areas of the grids are greater than $50 \%$ of the total area. They develop reinforcing strength at low strain levels, such as $2 \%$. More recently, triaxial geogrids (Fig. 2) are commercially produced and distributed.

Over the last 25 years, geogrids have been extensively used for the construction of earth-supported and earth-retaining structures such as mechanically stabilized earth (MSE) retaining walls, steep slopes, and other structures. A less familiar, but increasingly popular, adaptation of this technology is reinforced soil foundations (RSF). Here as the term implies the layered composite of granular fill and layers of polymeric reinforcements act like a beam thereby reducing unit stresses in the foundation soil beneath shallow spread footings. Geogrids have also been used as reinforcement in the construction of highways and airfields, where most applications are as a singular layer within or at the bottom of base or subbase granular fill. Design and construction protocol are well established in this fields $[8,20,21]$. As such, the bulk of this knowledge has been applied to paved and unpaved structures carrying rubber-tired traffic such as trucks and aircraft. The purpose of this paper is to highlight and summarize certain aspects of using geogrids as reinforcement in the construction of railroad beds and ballasts to improve their performance and structural integrity under rail traffic. Theoretical and experimental studies on this subject, either in the field or in the laboratory, are relatively scarce. Some case histories will also be briefly discussed showing the advantages of geogrid reinforcement as related to safety and maintenance of railroad tracks.

\section{Reinforcement mechanism}

Generally speaking, geogrids are used in one of two ways to reinforce track bed materials. When included at the bottom or within a ballast layer (Fig. 3), the primary benefit is an extension of the maintenance cycle, i.e., the period between ballast cleaning and replacement operations. The second way geogrids are used beneath a rail line is to reinforce the sub-ballast (Fig. 4). In this case the primary purpose of the geogrids is to increase the effective bearing capacity of an underlying soft subgrade.

Several authors have studied the reinforcement mechanisms associated with the interaction of geogrids and unbound aggregate. Perkins [14], for example, suggested
Fig. 1 Extruded uniaxial and biaxial geogrid

Fig. 2 Triaxial geogrid
Uniaxial geogrid

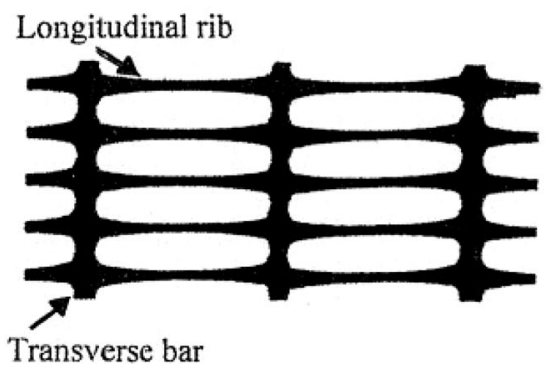

Transverse bar

\section{Biaxial geogrid}

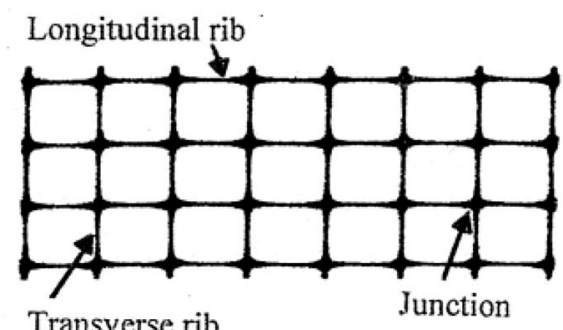

Transverse rib

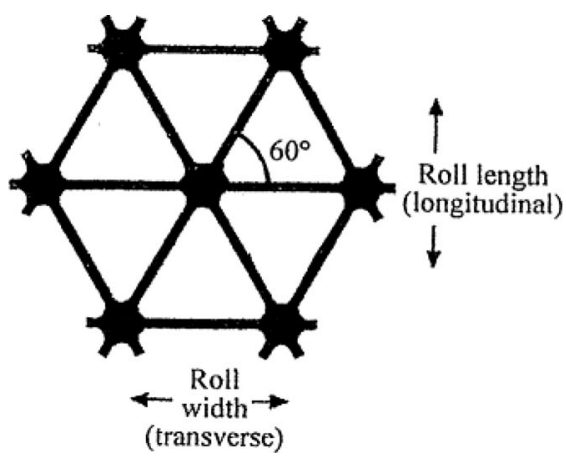




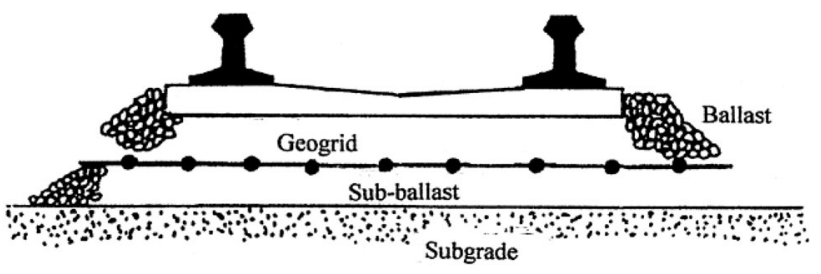

Fig. 3 Geogrid reinforcement of the ballast layer for maintenance reduction

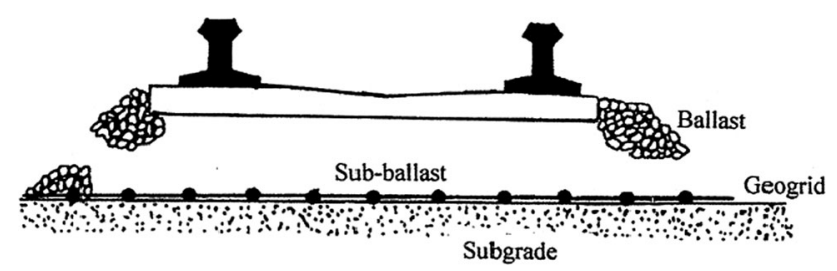

Fig. 4 Bearing capacity improvement by placement of the geogrid directly on the weaker subgrade

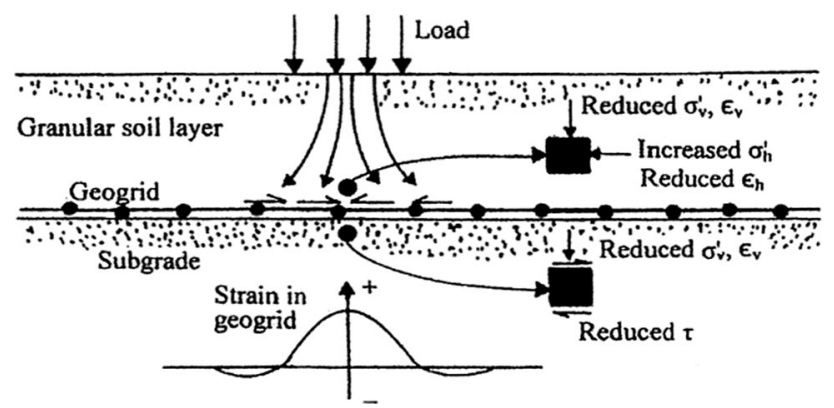

Fig. 5 Reinforcement mechanism of geogrid in granular soil over a subgrade (based on [14]). ( $\sigma_{\mathrm{v}}^{\prime}$ vertical effective stress, $\sigma_{\mathrm{h}}^{\prime}$ horizontal effective stress, $\varepsilon_{\mathrm{v}}$ normal strain in the vertical direction, $\varepsilon_{\mathrm{h}}$ normal strain in the horizontal direction, $\tau$ shear stress)

that there are four separate reinforcement mechanisms. These reinforcement mechanisms are shown in Fig. 5 and are described below:

(a) Confinement of the aggregate by the geogrid results in a reduction in the amount of lateral spreading.

(b) Confinement results in an increase in the lateral stress within the aggregate, thereby increasing its stiffness. This reduces the dynamic (recoverable) deformation for each load cycle.

(c) An increased modulus of the aggregate results in an improved vertical stress distribution onto the underlying subgrade. The effect is that the surface deformation will be less and more uniform.

(d) A reduction in the shear stress within the subgrade leading to lower vertical strain.

There are a limited number of studies presently available in the literature that provide a quantitative analysis of the reduced effective vertical stress $\left(\sigma_{\mathrm{v}}^{\prime}\right)$ that results from the inclusion of geogrid reinforcement in unbound aggregate. Shin et al. [17] conducted load tests on land reclaimed from the ocean for the construction of the Incheon International Airport in Korea. The field test arrangement essentially consisted of a plate load test (circular plate; diameter $B=0.3 \mathrm{~m}$ ) conducted on a granular mattress. Testing was undertaken both without and with geogrid reinforcement as shown in Fig. 6. The stress transmitted $\left(\sigma_{\max }^{\prime}\right)$ by the load on the plate below its center at a depth $d$ $(=0.45 \mathrm{~m})$ was measured by a pressure cell. The assumed stress distribution is shown in Fig. 7, with the boundary of stress, $\sigma_{\mathrm{v}}{ }^{\prime}$ inclined at an angle $\alpha$ to the vertical. This is similar to the so-called $2 \mathrm{~V}: 1 \mathrm{H}$ method used by geotechnical engineers to calculate the average effective vertical stress $\sigma_{\mathrm{av}}^{\prime}$. For 2:1 stress distribution $\alpha \approx 26.56^{\circ}$.

According to Boussinesq's theory, the effective vertical stress at a depth $d$ below the center of the plate is

$\sigma_{\max }^{\prime}=q\left\{1-\frac{1}{\left[\left(\frac{B}{2 d}\right)^{2}+1\right]^{1.5}}\right\}$,

where $q=$ load per unit area of the plate and $B=$ diameter of the test plate. Referring to Fig. 7, the average effective vertical stress is

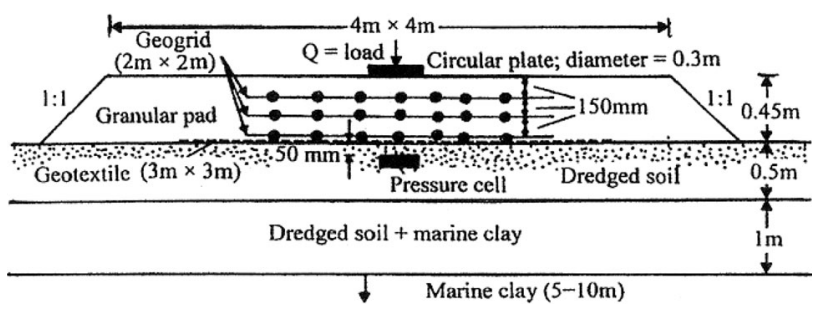

Fig. 6 Load test arrangement of Shin et al. [17] on reclaimed land

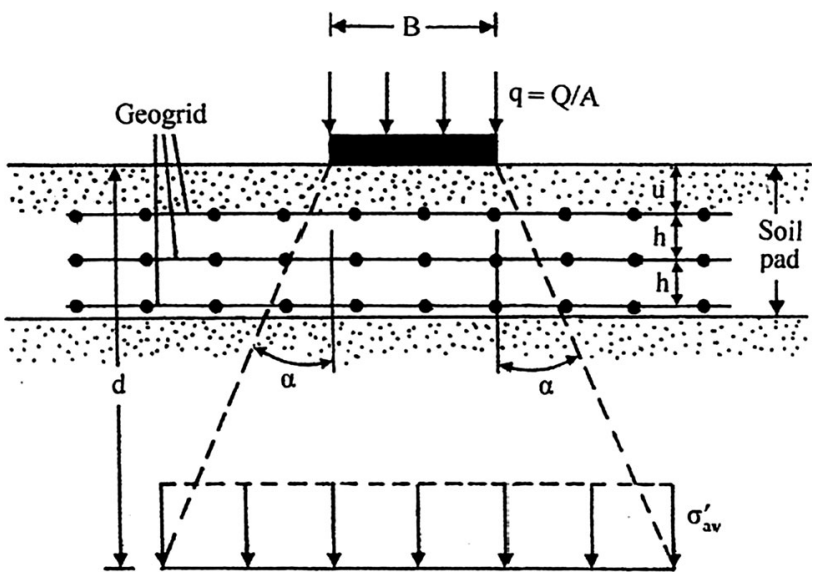

Fig. 7 Simplified assumption of stress distribution in soil under a uniformly loaded circular area located over a geogrid-reinforced granular soil pad 


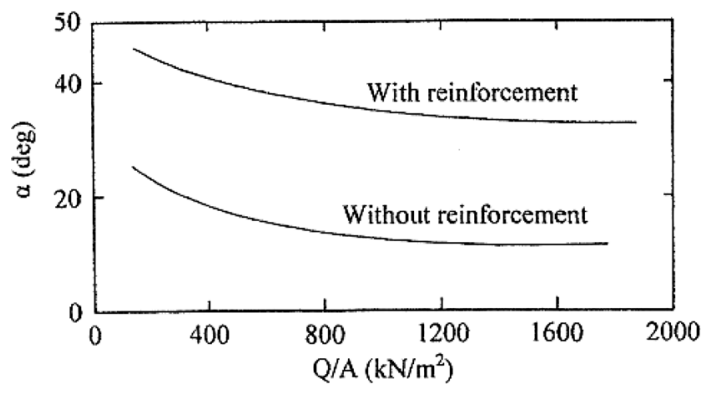

Fig. 8 Plot of $\alpha$ vs. $q=Q / A$ (adapted after [17])

$\sigma_{\mathrm{av}}^{\prime}=\frac{q B^{2}}{(B+2 d \tan \alpha)^{2}}$.

For $d / B \leq 2$ and $\alpha=26.56^{\circ}$ (2:1 distribution)

$\sigma_{\mathrm{av}}^{\prime} \approx 0.9 \sigma_{\text {max }}^{\prime}$.

Hence, from Eqs. (2) and (3), the magnitude of $\alpha$ can be approximated as

$\alpha \approx \tan ^{-1}\left[\frac{\left(\frac{q B^{2}}{0.9 \sigma_{\max }^{\prime}}\right)^{0.5}-B}{2 d}\right]$.

Based on the measured value of $\sigma_{\max }^{\prime}$, the approximate variations of $\alpha$ with $q=Q / A$ were calculated and are shown in Fig. 8. From this figure the following conclusions can be drawn:

(a) For a given arrangement of geogrid reinforcement and $q$, the magnitude of $\alpha$ increases as compared to the unreinforced case. A larger value of $\alpha$ implies a decrease in the magnitude of $\sigma_{\mathrm{av}}^{\prime}$.

(b) For a given reinforcement arrangement, $\alpha$ is a function of $q$.

A similar conclusion was also reached by Gabr et al. [7] based on large-scale model tests in the laboratory.

\section{Performance of geogrid-reinforced ballast}

\section{Queens University Study, Ontario, Canada}

Bathurst and Raymond [3] reported results from a largescale model test program comprising a single tie/ballast system constructed over an artificial subgrade with variable compressibility (also see [4]). The tie (width $250 \mathrm{~mm} \times$ $150 \mathrm{~mm}$ deep) was laid on a ballast layer having a thickness of $450 \mathrm{~mm}$. A biaxial geogrid was used for reinforcement of the ballast. The depth of reinforcement below the tie $\left(D_{\mathrm{r}}\right)$ ranged from 50 to $200 \mathrm{~mm}$. Cyclic loads (peak load of $85 \mathrm{kN}$ per rail tie) with frequencies varying from 0.5 to $3 \mathrm{~Hz}$ were applied to the tie. This provided a bearing

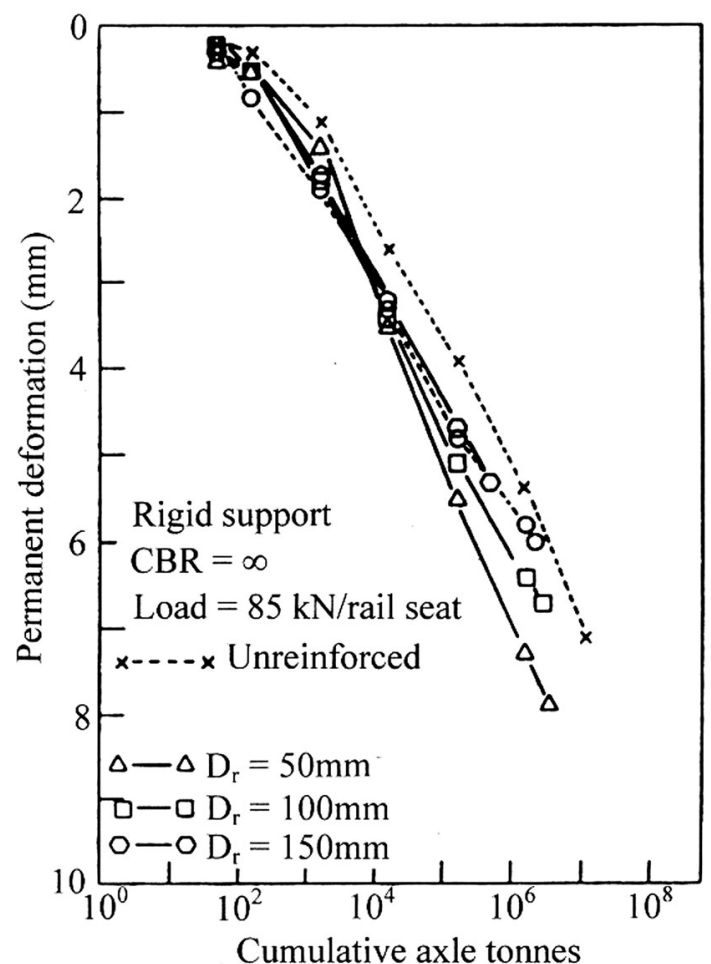

Fig. 9 Variation of permanent deflection with cumulative axle tonnes for CBR $=\infty$-tests of Bathurst and Raymond [3]

pressure of $370 \mathrm{kN} / \mathrm{m}^{2}$ which represents a typical magnitude of dynamic load felt by ballasts directly beneath the tie for track modulus between 14 and $84 \mathrm{MN} / \mathrm{m} / \mathrm{m}$ of rail [15].

Tests were subjected to a maximum number of load repetitions that were equivalent to 2-20 million cumulative axle tonnes in track. Figures 9, 10 and 11 show the variation of permanent deformation with cumulative axle tonnes, respectively, for rigid subgrade support $(\mathrm{CBR}=\infty)$, flexible subgrade support $(\mathrm{CBR}=39)$, and very flexible subgrade support $(\mathrm{CBR}=1)$. It is obvious from these figures that the inclusion of geogrid in the ballast layer reduces the permanent deformation for any given cumulative axle tonnes. However, the effect becomes progressively pronounced with the decrease in CBR of the subgrade. This fact is also clearly demonstrated in Fig. 12, which is for $D_{\mathrm{r}}=100 \mathrm{~mm}$.

The transfer to stress is a function of the location of the geogrid in relation to the bottom of the tie. Figures 13 and 14, which are based on the results shown in Figs. 10, 11 and 12 , show the relationships between cumulative tonnes, permanent deformation, and reinforcement depth $D_{\mathrm{r}}$. Based on the plots shown in Figs. 13 and 14 it appears that the optimum value of $D_{\mathrm{r}}$ varies between 50 and $100 \mathrm{~mm}$. However, this depth may be unsatisfactory from practical considerations, that is, construction and maintenance. Hence, a value of $D_{\mathrm{r}} \approx 200 \mathrm{~mm}$ is probably more acceptable. 


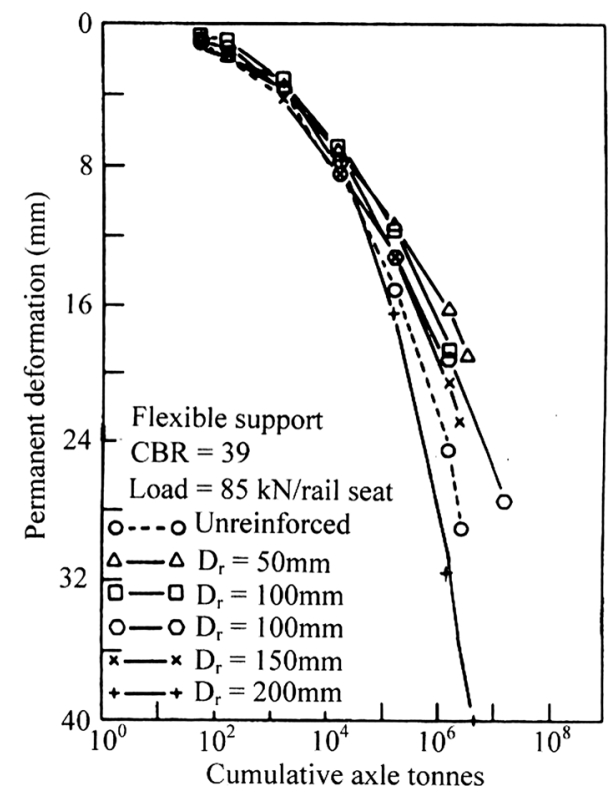

Fig. 10 Variation of permanent deflection with cumulative axle tonnes for CBR = 39—-sts of Bathurst and Raymond [3]

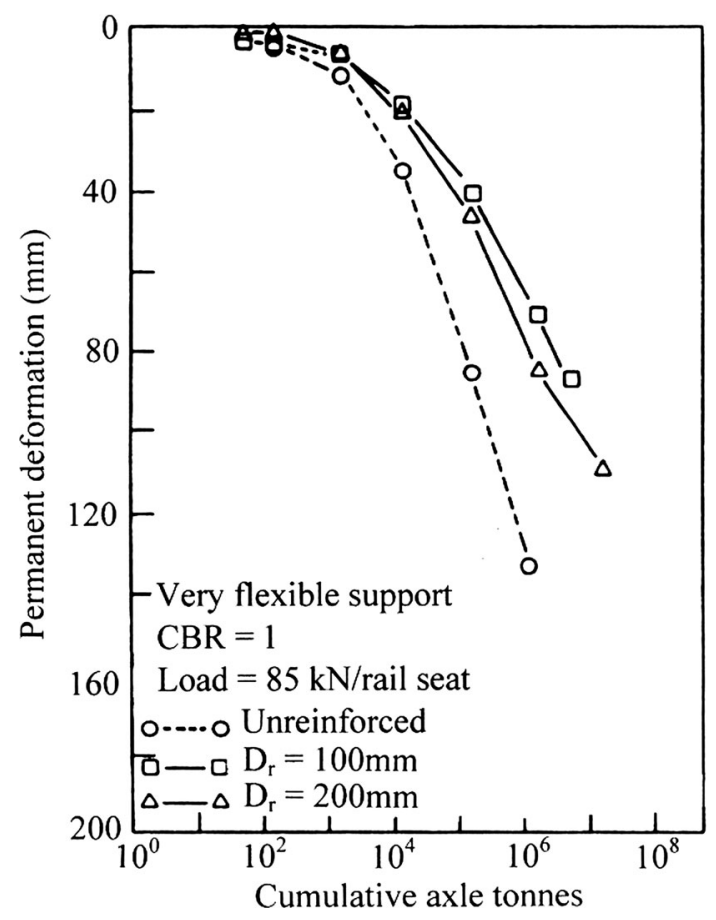

Fig. 11 Variation of permanent deflection with cumulative axle tonnes for CBR $=1$-tests of Bathurst and Raymond [3]

\section{British Rail Study, Derby, United Kingdom}

To evaluate the beneficial effects of using geogrid reinforcement in ballast sections, the British Rail Research conducted three large-scale laboratory tests using a rolling load rig [10]. Two of these tests were carried out using extruded biaxial geogrid reinforcement (Fig. 15) in the

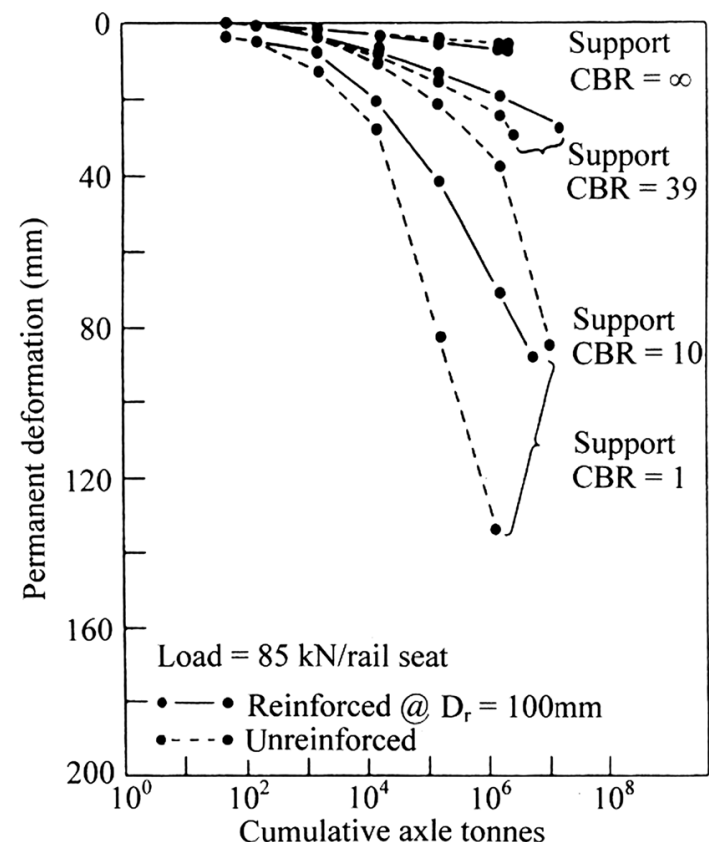

Fig. 12 Results from Queens University study $\left(D_{\mathrm{r}}=100 \mathrm{~mm}\right)$

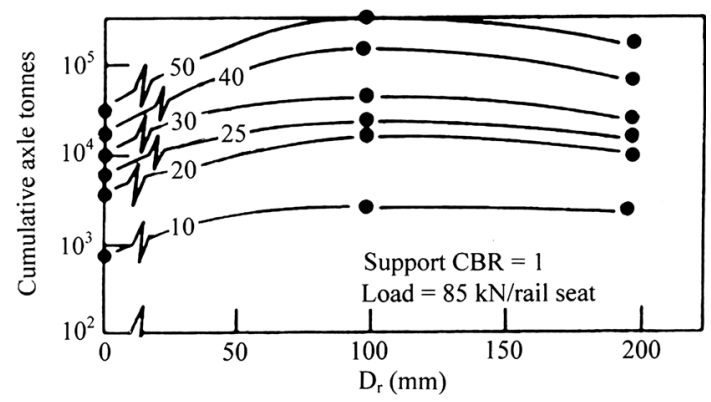

Fig. 13 Determination of the optimum geogrid location (after [3]) $(\mathrm{CBR}=1)$

ballast layer. A third test was undertaken without reinforcement and acted as the control section for comparison. In all three tests, a simulated soft subgrade was placed under the ballast and the results were compared with a similar unreinforced test conducted using the solid floor of the test facility; this test was undertaken to determine how the test sections conducted on a soft subgrade compared with a section constructed on a competent formation. The test arrangement is shown schematically in Fig. 16. The weight of the rolling load rig used could be varied from 8 to $40 \mathrm{t}, 90 \%$ of which was carried by the main central axle. For each test section, 2 million gross tonnes (MGT) of trafficking was undertaken.

In the UK, the performance of a rehabilitated ballast section following subsequent trafficking is defined using the parameters, initial lift and residual lift. These are defined in Fig. 17. The four tests undertaken in the British Rail Research study were as follows: 


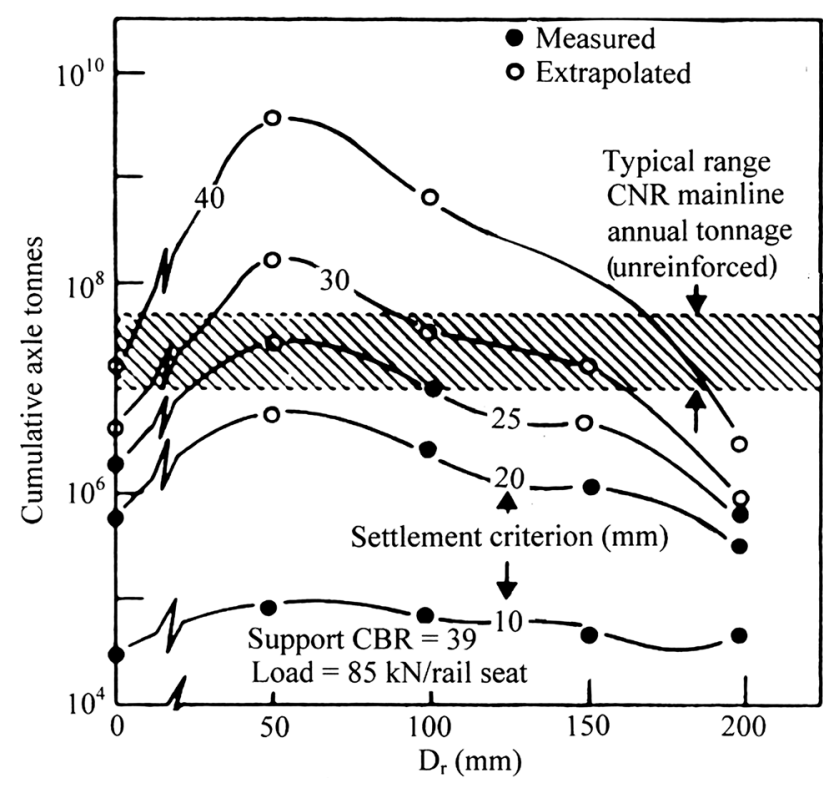

Fig. 14 Determination of the optimum geogrid location (after [3]) $(\mathrm{CBR}=39)$

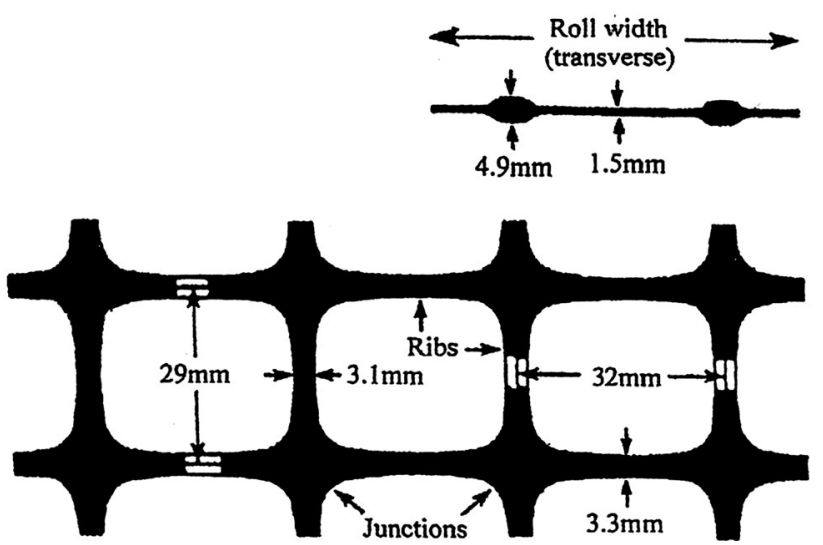

Fig. 15 Extruded geogrid used in the British Rail Research tests

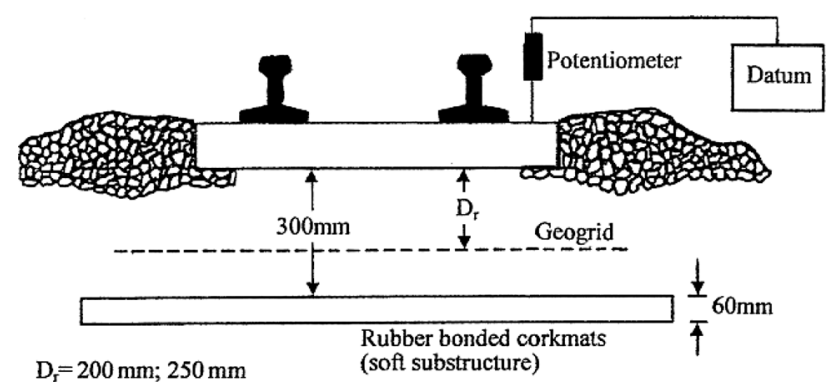

Fig. 16 Schematic diagram of the cross section of traffic with simulated soft subgrade for the British Rail Research tests

(a) Control section-soft subgrade, no reinforcement,

(b) reinforced section-soft subgrade, geogrid $50 \mathrm{~mm}$ above the ballast-subgrade interface $\left(D_{\mathrm{r}}=\right.$ $250 \mathrm{~mm}$ ), (c) reinforced section-soft subgrade, geogrid $100 \mathrm{~mm}$ above the ballast-subgrade interface $\left(D_{\mathrm{r}}=200 \mathrm{~mm}\right)$, and

(d) control section-solid subgrade.

The main results from the British Rail Research tests are presented in Fig. 18. Theoretically, absolutely perfect performance post-rehabilitation would be represented by the situation whereby the initial lift and residual lift were equal; this would mean that there was no further settlement of the track following further trafficking. In reality, the best possible performance is depicted by line 4 in Fig. 18 as this depicts the performance of a rehabilitated track constructed on a completely rigid foundation. The further to the right of this line, the more settlement has occurred post-rehabilitation. The main conclusion that can be drawn from these results is that the performance of reinforced ballast constructed on a soft subgrade approaches that of the same ballast section constructed on a solid formation.

During the British Rail Research tests, individual rail ties were instrumented to monitor the elastic deformation that occurs as the train transfers its load during trafficking. A typical set of results for a reinforced and unreinforced test section constructed on a soft subgrade are shown in Fig. 19. The effect of the reinforcement in

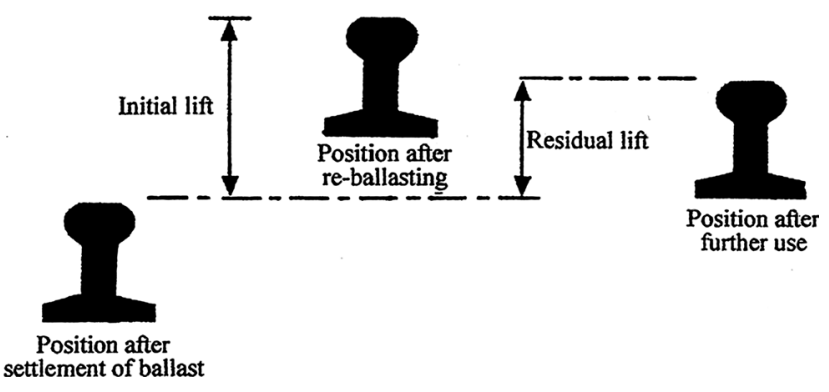

Fig. 17 Definition of initial lift and residual lift

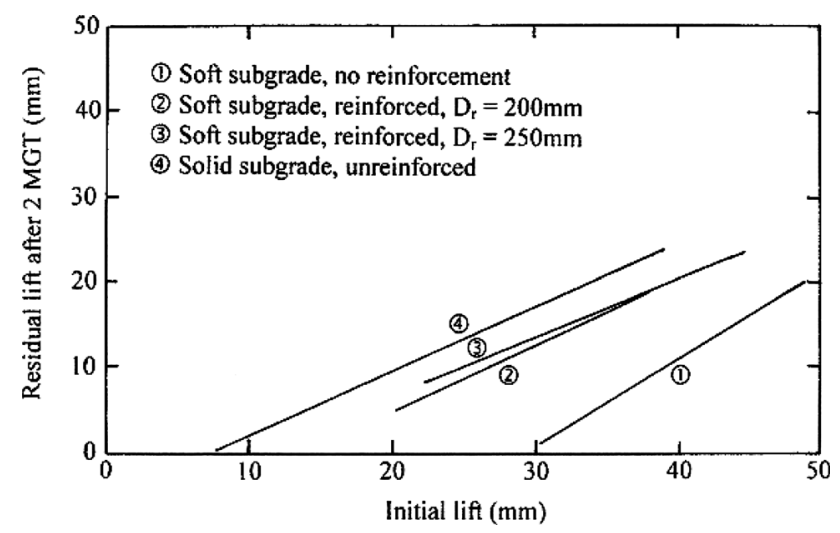

Fig. 18 Performance of ballast sections-British Rail Research tests 


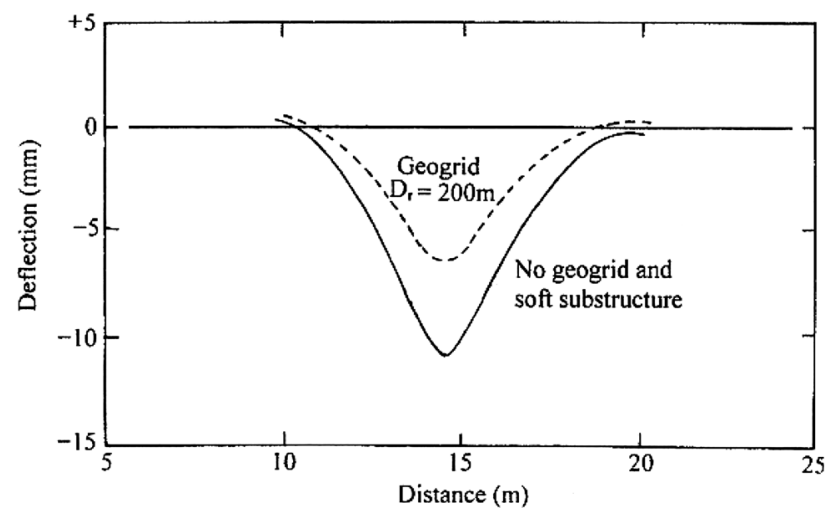

Fig. 19 Dynamic track deflection for unreinforced and reinforced ballast sections-British Rail Research tests

creating a stiffer ballast section and reducing the stress imposed on the underlying compressible layer is clear, with a reduction of approximately $50 \%$ in the dynamic deformation observed for a given load cycle. Based on this study and other observations, the Network Rail of UK (2005) has provided guideline specifications for designing railroad beds with geogrid reinforcement in the ballast. This is discussed in more detail in "Network rail (UK) design specifications".

\section{Performance of geogrid-reinforced base course under cyclic load}

Atalar et al. [2] undertook a study related to the planning and construction of a high-speed $(385 \mathrm{~km} / \mathrm{h})$ rail line extending from Seoul to Pusan, South Korea. This study was primarily intended to improve the bearing capacity of soft subgrade (similar to that shown in Fig. 4). The testing equipment and layer thicknesses are shown schematically in Fig. 20. A biaxial geogrid was used for these tests. The subgrade soil had a CBR of 3. A rail tie with a width of $270 \mathrm{~mm}$ was used for the application of a cyclic load (Fig. 21) to the test section. The maximum cyclic stress to which the tie was subjected was approximately $14 \%$ greater than that anticipated in the field. The variation in the amount and type of geogrid reinforcement used in the four tests undertaken is presented in Table 1.

The results of the testing are presented in Fig. 22. The performance benefits resulting from the inclusion of geosynthetic in the various aggregate layers is obviousfollowing 500,000 load cycles, settlement in the reinforced sections was reduced by 47,58 and $80 \%$ for tests 2,3 and 4 , respectively.

More recently, Indraratna et al. [9] also described certain aspects of improvement of bearing capacity by geogrid reinforcement of base course.

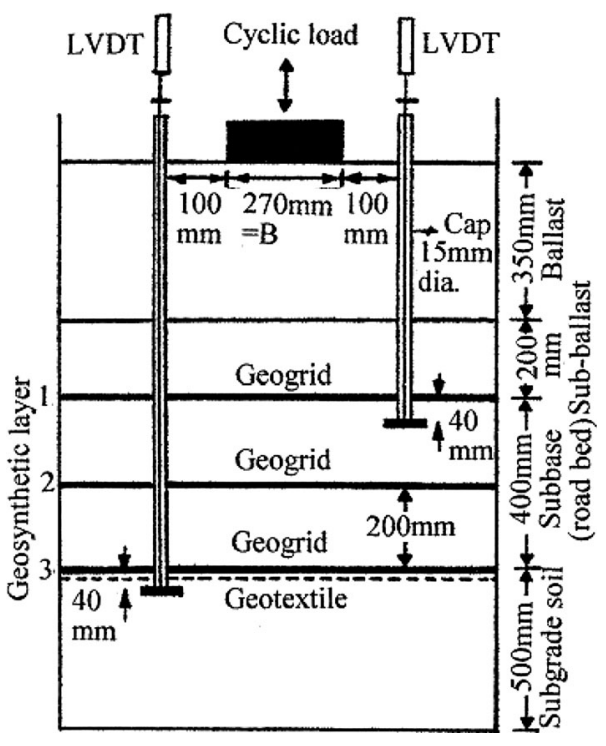

Fig. 20 Test arrangement-Atalar et al. [2]

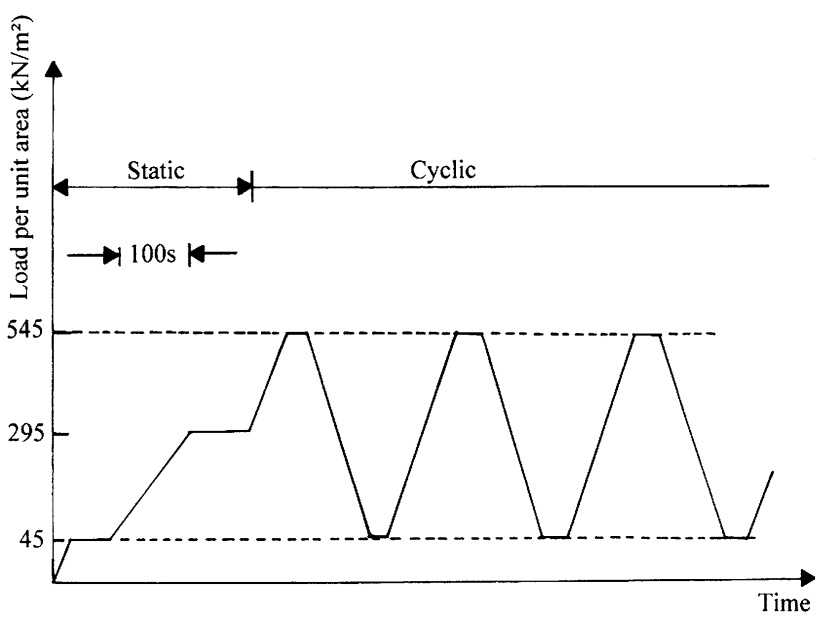

Fig. 21 Cyclic load application-Atalar et al. [2]

Table 1 Sequence of model tests reported by Atalar et al. [2]

\begin{tabular}{lll}
\hline Test no. & $\begin{array}{l}\text { Reinforced/ } \\
\text { unreinforced }\end{array}$ & $\begin{array}{l}\text { Reinforcement details } \\
\text { (see Fig. 20) }\end{array}$ \\
\hline 1 & Unreinforced & - \\
2 & Reinforced & Layer 1 only \\
3 & Reinforced & Layers 1 and 2 \\
4 & Reinforced & Layers 1,2 and 3 \\
\hline
\end{tabular}

\section{Parametric study for selection of geogrid}

Brown et al. [5, 6] reported results of full-scale tests conducted at Nottingham Transportation Engineering Center at the University of Nottingham (UK) that were intended to identify the key parameters that influence 


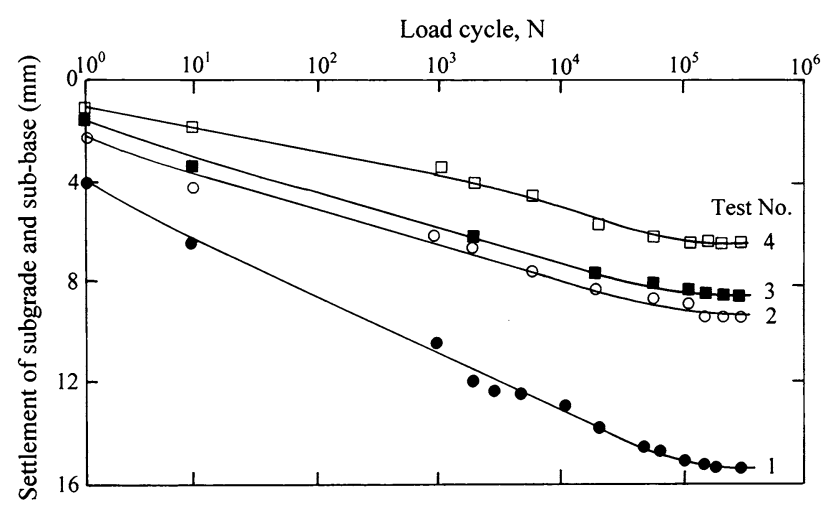

Fig. 22 Settlement of subgrade and sub-base with load cycle-Atalar et al. [2]

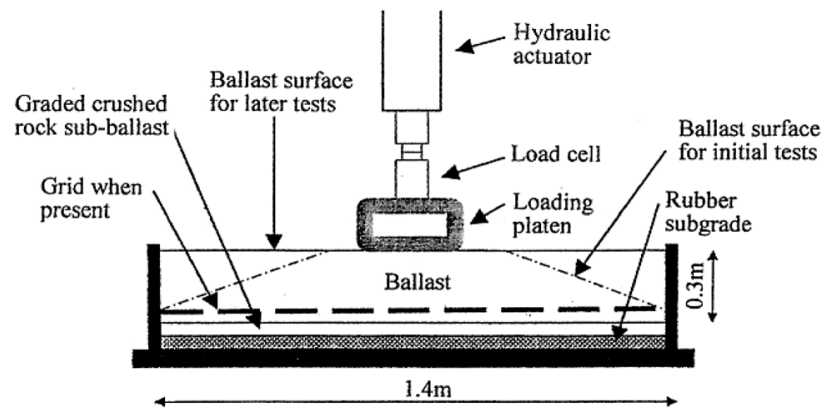

Fig. 23 Schematic diagram of the composite element test apparatus (after [6])

geogrid reinforcement of railway ballasts (similar to that shown in Fig. 3). Some of the results were also summarized by Thom [19]. These tests were conducted in a Composite Element Test apparatus (shown in Fig. 23). Repeated loads of $20 \mathrm{kN}$ at $2 \mathrm{~Hz}$ were applied for 30,000 cycles through a loading platen consisting of a section of rectangular hollow steel $250 \mathrm{~mm}$ wide $(0.7 \mathrm{~m}$ long) representing the sleeper. This gave a contact stress of $114 \mathrm{kN} / \mathrm{m}^{2}$ beneath the berm which is about half of the maximum expected on an actual track. Extruded biaxial geogrids with square apertures and various nominal tensile strength were used for the tests. A summary of the major findings of the test program follows:

\section{Resilient tensile stiffness of geogrids (R)}

Resilient tensile stiffness is probably a more appropriate parameter of geogrid for design purposes as compared to nominal tensile strength and it is defined as

$R=\frac{\text { Amplitude of cyclic load per meter width }}{\text { Amplitude of tensile strain }}$.

The amplitude of cyclic load should be below $10 \%$ of the tensile strength of the geogrid. Figure 24 shows the variation of $R$ with nominal tensile strength $T$ of geogrid having $65 \mathrm{~mm}$ nominal aperture size. The results show that there is a nonlinear relationship between stiffness and nominal tensile strength.

\section{Influence of aperture size of geogrid on settlement}

Figure 25 shows a plot of aperture size with settlement at 30,000 load cycles. The numbers next to each point are the nominal tensile strength of geogrid (in $\mathrm{kN} / \mathrm{m}$ ). It is obvious from the figure that tensile strength may not be necessarily the parameter alone which controls the settlement. For these tests it appears that the optimum dimension of the aperture for minimizing settlement is $60-80 \mathrm{~mm}$ with an average of $70 \mathrm{~mm}$. For the tests the nominal aggregate size was $50 \mathrm{~mm}$. Thus, for optimum performance, the ratio is

$\frac{\text { Aperture size of geogrid }}{\text { Nominal aggregate size }}=\frac{70 \mathrm{~mm}}{50 \mathrm{~mm}}=1.4$.

It is also interesting to point out that McDowell et al. [11] conducted a theoretical study that involved the application of discrete element method for modeling of both grid and ballast. One of the key findings of this study

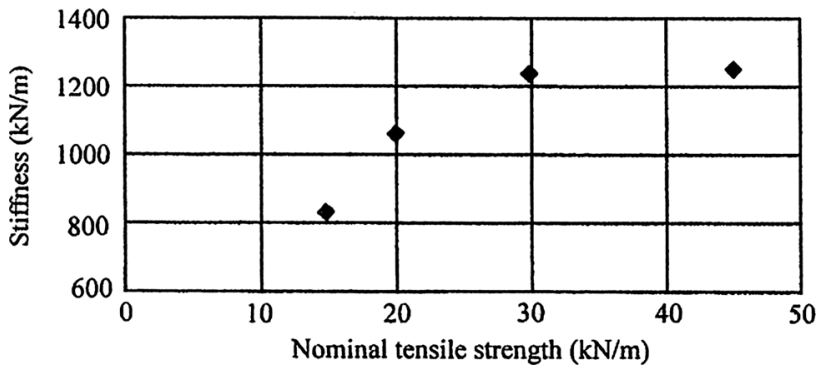

Fig. 24 Relationship between low strain stiffness $(R)$ and nominal tensile strength for the $65 \mathrm{~mm}$ nominal aperture polymer geogrids (after [6])

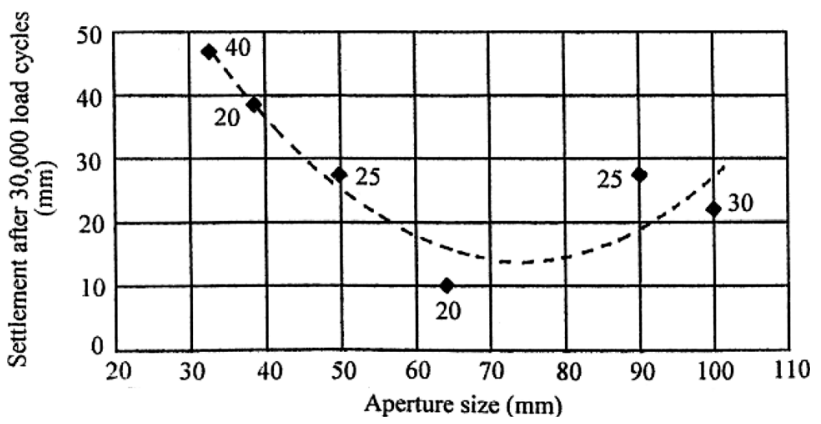

Fig. 25 Relationship between settlement after 30,000 cycles and geogrid aperture size (after [6]). Numbers indicate tensile strength of geogrids in $\mathrm{kN} / \mathrm{m}$ 
was that the optimum ratio of grid aperture size to the nominal size of aggregate is about 1.4. This is essentially the same as that found from the experimental work of Brown et al. [6].

\section{Influence of geogrid stiffness}

The influence of geogrid stiffness of the settlement at 30,000 cycles for low overburden pressure is shown in Fig. 26. The geogrid used had aperture size of $65 \mathrm{~mm}$ but varying stiffness $(R)$. This indicates, somewhat counter intuitively, that performance deteriorates with higher stiffness of geogrids. Further tests were carried out by Brown et al. [5] under higher overburden pressure which showed that, indeed, performance improved with higher stiffness of geogrid. Thus, given the nature of the geogrids, this suggests that bending stiffness in the plane of the geogrid may be an important parameter. Under low overburden, the geogrid would tend to resist the compaction process inhibiting the development of good interlock with the ballast particles.

\section{Effect of geogrid reinforcement in ballast for extension of maintenance cycles}

Figure 27 shows the variation of settlement vs. number of load cycles for both unreinforced and geogrid-reinforced ballast. The geogrid used for these tests had a nominal aperture size of $65 \mathrm{~mm}$ and tensile strength of $30 \mathrm{kN} / \mathrm{m}$. The tests were conducted up to one million cycles. It can be seen from the figure that, for about $7.5 \mathrm{~mm}$ settlement, the cyclic load needed for reinforced ballast is about 2.5 times more as compared to that for unreinforced ballast. This implies that, in the field, geogrid reinforcement in the ballast extends the time for maintenance cycles. Using this geogrid, good performance has also been demonstrated by early results from a field trial on the West Coast Main Line (UK) as reported by Sharpe et al. [16].

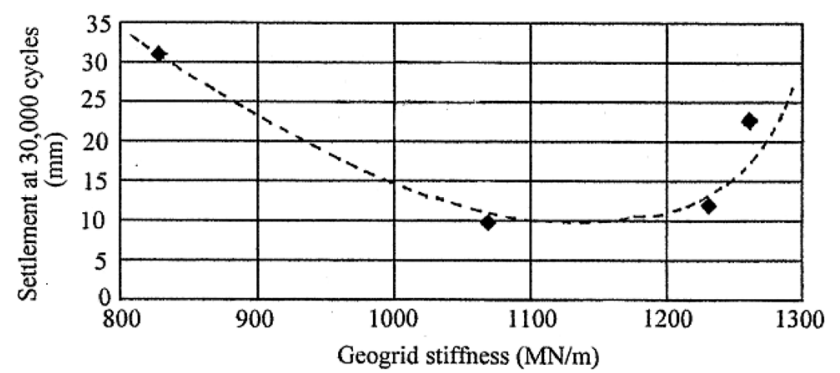

Fig. 26 Relationship between settlement and geogrid stiffness for low overburden tests (after [5])

\section{Some case histories}

There has been a steady increase in the use of geogrids as ballast or sub-ballast reinforcement since these materials were introduced more than 25 years ago. In recent times, their use has become particularly widespread in Germany and parts of Eastern Europe. The following case histories outline some of the projects where geogrid reinforced rail beds were used; in each case, the value brought to the end user is also described.

\section{Heavy Rail Project, Millstead, AL, USA}

Walls and Galbreath [22] describe a project involving the reconstruction of a $2 \mathrm{~km}$ long rail track near Millstead, AL. The track section was owned and operated by CSX Transportation, one of the Class I railroad companies in the US. The track was founded on poor quality soils consisting of interbedded sand and weak clay; the high groundwater table added to the challenging ground conditions.

This stretch of rail line had a long history of problems being encountered. The heavy rail traffic resulted in excessive settlement of the track due to progressive shear failure of the subgrade, heaving of shoulders and pumping of fines through the ballast. At one point of time, maintenance work was being undertaken every $2-4$ weeks, and an $8 \mathrm{~km} / \mathrm{h}$ speed restriction was in permanent effect.

Rather than adopt the alternative and more costly solution of relocating the track, the decision was made to stabilize the track foundation using geosynthetics. A layer of geotextile $\left(380 \mathrm{~g} / \mathrm{m}^{2}\right)$ placed on the existing sub-ballast to provide additional separation, and this was immediately overlain with a layer of extruded biaxial geogrid and a $300 \mathrm{~mm}$ thick ballast layer. The project was completed in December 1983. After 3 years of further rail trafficking, no track stability problems had been encountered at the time of reporting (i.e. 1987) and the maximum speed was raised to $56 \mathrm{~km} / \mathrm{h}$.

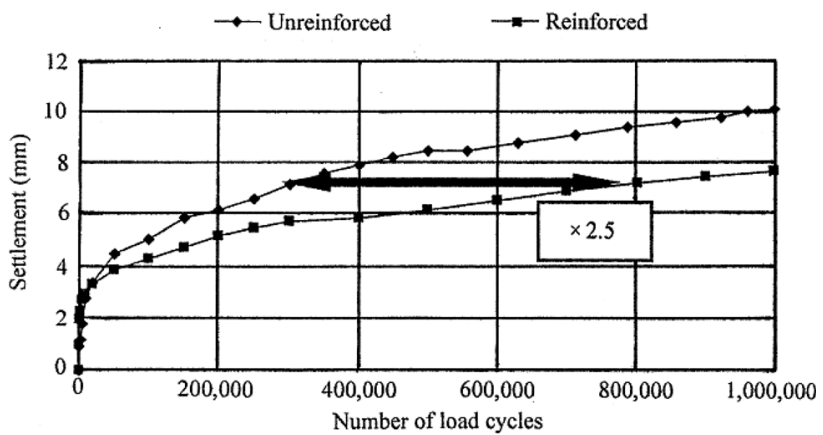

Fig. 27 Plot of settlement vs. number of load cycles (after [6]). Geogrid $-65 \mathrm{~mm}$ aperture and $30 \mathrm{kN} / \mathrm{m}$ tensile strength 


\section{Australian National Rail Project, Cavan, South Australia}

Alexander and Sanders [1] provide details of a rehabilitation project that involves a $700 \mathrm{~m}$ long section of rail track located at Cavan, near Adelaide in South Australia. The line was owned and operated by the Australian National Rail Authority. Reconstruction was necessary due to the underlying poor ground conditions-clay soil (typical undrained shear strength $100 \mathrm{kN} / \mathrm{m}^{2}$ ), combined with a high ground water table. The construction involved placing a layer of geotextile over the subgrade and then placing a layer of geogrid on top of the geotextile. A 450-m thick ballast layer was then placed over the geogrid layer, after which a second layer of geogrid was place to, in effect, encapsulate the subballast and form a raft. Further ballasts were then placed to form the normal railway ballast formation. At the time of reporting by the authors (in 1994), no noticeable movement or settlement of track had occurred.

\section{Czech Republic Rail Project}

The upgrading of rail lines in the former Communist countries of Eastern Europe during the last 15-20 years has involved some of the most extensive rail infrastructure investment anywhere in the world. The railway sections in the Czech Republic are divided into four corridors. Corridors I, II, III and IV have lengths of 430, 240, 540 and $200 \mathrm{~km}$ respectively. Upgrading of $92 \mathrm{~km}$ of Corridor I (construction time 1996-2003) and $32 \mathrm{~km}$ of Corridor II (construction time 1998-2005) were typical of this work [12]. The track was required to carry $160 \mathrm{~km} / \mathrm{h}$ high speed trains but in many cases the subsoil conditions were unfavorable-low bearing capacity subgrade and high groundwater were commonly encountered.

Consideration was given to using cement stabilization to improve the subgrade but this was quickly discounted due to the prevailing climatic conditions - heavy rain for prolonged periods is common in this area. There were also environmental concerns associated with chemical stabilization techniques. Instead, the use of biaxial geogrids beneath and, in some cases, within the ballast/sub-ballast offered the opportunity to avoid excavation of the subgrade and also reduce the quantity of aggregate required. This method of stabilization also allowed work to continue during the bad weather while achieving the target bearing capacity for the track foundation.

The geogrid and geotextile used in the construction had the following specifications:

- Tensile strength (transverse and longitudinal)—30 kN/ $\mathrm{m}$ (min).

- Tensile strength at $3 \%$ elongation (transverse and longitudinal) $-10 \mathrm{kN} / \mathrm{m}$ (min).

\section{Ground stabilization for rail track in Nagykanizsa, Hungary}

Maintenance of the rail track in Nagykaisza, Hungary, was frequent and expensive due to permanent penetration of fine particles from the embankment body into the ballast layer and ballast stone into weak sub-soil. As a short-term measure, monthly maintenance of the railway section in Nagykanizsa was required. However, in 2000, a permanent solution was needed to solve the problem of the penetration of fine particles from the embankment body into the ballast layer by using geotextile and geogrid. The solution started with excavation of the old ballast layer including $10 \mathrm{~cm}$ below the standard thickness of the layer. Then, a layer of biaxial geogrid with a light separation geotextile was installed beneath, directly on the weak soil and covered with new ballast stone (Fig. 28). Stone particles penetrated the apertures of the geogrid and interlocked. With this mechanism, horizontal movements of the stones generated by cycling loading of the track were retained. The ballast layer was stabilized and the mixing of stones and fine particles ended. After installation of the geogrid, measurements on the rail track showed a significant reduction of deformations compared with the situation previously (Fig. 29). More details are available in Case Study Ref. 058 of Tensar International [18].

\section{Network rail (UK) design specifications}

The use of geogrids as reinforcement is beginning to be incorporated into the railroad design codes of several countries, particularly in Europe. As an example, following is a summary of the guidelines adopted by the network rail [13]. According to the guidelines, "geogrid reinforcement"
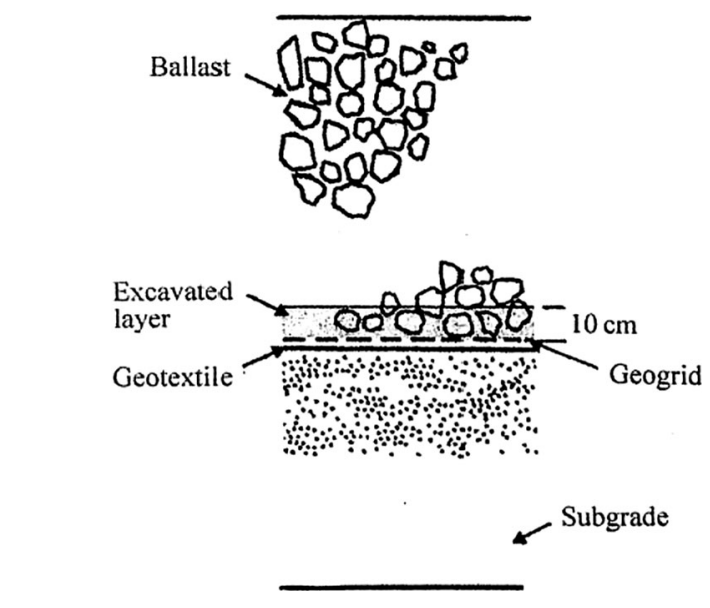

Fig. 28 Stabilization of ground for rail track in Nagykanizsa, Hungary (2000) 


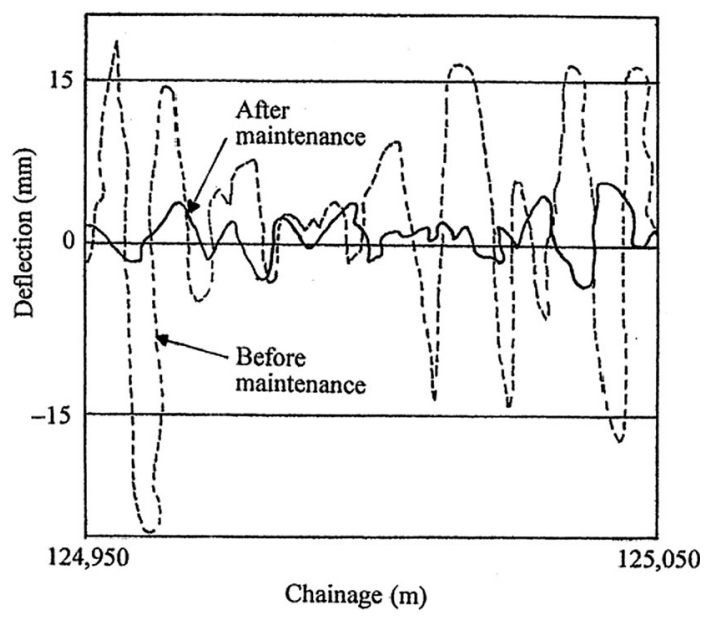

Fig. 29 Deformation of rail track before and after maintenance (Nagykanizsa, Hungary)

Table 2 Required dynamic sleeper support stiffness $(K)$ for maximum axle load of 25 tonnes (after Network [13])

\begin{tabular}{lc}
\hline & $\begin{array}{l}\text { Minimum dynamic } \\
\text { sleeper support stiffness } \\
(K) \mathrm{kN} / \mathrm{mm} / \text { sleeper end }\end{array}$ \\
\hline Absolute value & 30 \\
Existing main lines & 30 \\
With geogrid reinforcement & 60 \\
Without reinforcement & \\
New track & 60 \\
Up to $100 \mathrm{mph}$ & 100 \\
Above $100 \mathrm{mph}$ & \\
\hline
\end{tabular}

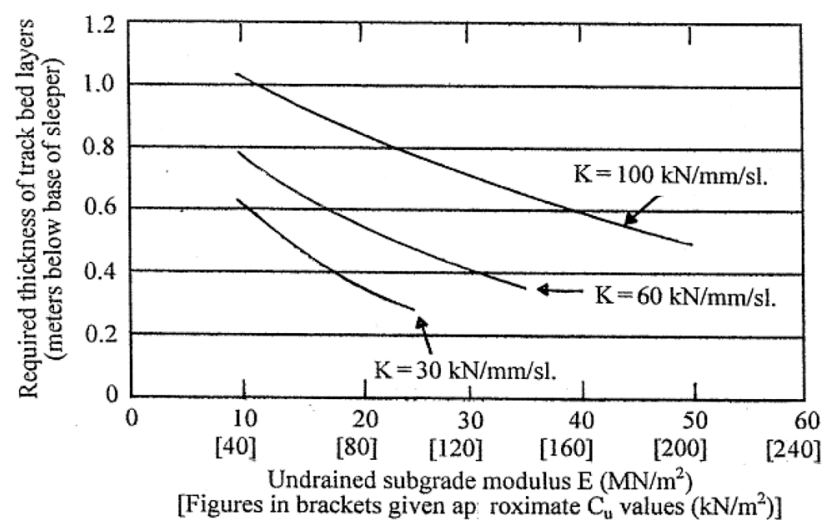

Fig. 30 Determination of thickness of track bed layers (Network [13])

is defined as "a plastic mesh with high tensile stiffness, used to reduce ballast movement over soft ground." The required dynamic sleeper support stiffness $(K)$ is given in Table 2.
The dynamic sleeper support stiffness $(K)$ is defined as "the peak load divided by the peak deflection of the underside of a rail seat area of an unclipped sleeper subjected to an approximately sinusoidal pulse load at each rail seat; the pulse load being representative in magnitude and duration of the passage of a heavy axle load at high speed." Accordingly, Fig. 30 can be used to obtain the required track bed thickness with known values of $K$ and undrained subgrade modulus $E$ (or undrained cohesion $C_{\mathrm{u}}$ ).

\section{Conclusions}

A review of the present state-of-the-art for using geogrids as reinforcement in railway track bed construction has been presented. Depending on the required benefit, the reinforcement can be placed within the ballast layer, at the interface of the ballast and sub-ballast layer, and/or directly on the subgrade. Based on the laboratory testing described and extensive experience in the use of geogrids on projects throughout the world, the following general conclusions can be drawn.

(a) Geogrid reinforcement reduces the rate of permanent settlement of tracks, particularly on soft subgrades.

(b) The elastic deformation of the track for an individual load cycle is reduced due to the stiffening effect of the reinforcement.

(c) Geogrid reinforcement extends the interval between maintenance operations.

(d) The minimum practical depth below ties at which a geogrid reinforcement laver can be placed is about $200 \mathrm{~mm}$. At this depth, the reinforcement benefits are still very significant.

(e) The optimum nominal aperture size of geogrid should be about 1.4 times the nominal ballast size.

(f) When geogrids are used for ballast reinforcement, their bending stiffness may be an important parameter as related to the extension of the maintenance cycle. This requires further evaluation.

Acknowledgments The author would like to thank the organizers of the " 4 th International Conference on New Developments in Soil Mechanics and Geotechnical Engineering, 2-4 June 2016, Near East University, Nicosia, North Cyprus" for their permission to publish this lecture on the Innovative Infrastructure Solutions Journal as a review article.

\section{References}

1. Alexander WW, Sanders LJ (1994) Geogrid encapsulation of railway formation. In: Proceedings of the fifth international conference on geotextiles, geomembranes, and related products, Singapore, pp 167-169 
2. Atalar C, Shin EC, Das BM, Kim DH (2001) Settlement of geogrid-reinforced railroad bed due to cyclic load. In: Proceedings, XV international conference on soil mechanics and geotechnical engineering, Istanbul, Turkey, pp 2045-2048

3. Bathurst RJ, Raymond GP (1987) Geogrid reinforcement of ballasted track. Transportation Research Record 1153. National Research Council, Washington, DC, pp 8-14

4. Bathurst RJ, Raymond GP, Jarret PM (1986) Performance of geogrid-reinforced ballast railroad track support. In: Proceedings, third international conference of geotextiles, Vienna, Austria, pp 44-48

5. Brown SF, Kwan J, Thom NH (2007) Identifying the key parameters that influence geogrid reinforcement of railway ballast. Geotext Geomembr 25(6):326-335

6. Brown SF, Thom NH, Kwan J (2006) Optimising the geogrid reinforcement of rail track ballast. In: Proceedings, railway foundations. University of Birmingham, UK, pp 346-354

7. Gabr MA, Dodson R, Collin JG (1998) A study of stress distribution in geogrid-reinforced sand. Geotechnical special technical publication 76, ASCE, pp 62-76

8. Giroud GP, Han J (2004) Design method for geogrid-reinforced unpaved roads; I: development of design method; II: calibration and applications. J Geotech Geoenviron Eng ASCE 130(8):775-797

9. Indraratna B, Nambalkar S, Rjuikiat-Kamjorn C (2011) Stabilisation of ballast and subgrade with geosynthetic grids and drains for rail infrastructure. In: Proceedings, international conference on advances in geotechnical engineering 2011, Perth, Australia, pp 99-112

10. Matharu MS (1994) Geogrids cut ballast settlement rate on soft substructures. Railway Gazette International, March

11. McDowell GR, Harireche O, Konietsky H, Brown SF, Thom NH (2006) Discrete element modeling of geogrid-reinforced aggregates. In: Proceedings, institute of civil engineering-geotechnical engineering, vol 159(GE1), pp 35-48
12. Mica L, Hubic P, Mynav J, Minar L (2000) Railway corridors construction using rigid geogrids reinforcement in the Czech Republic, In: Proceedings, second European conference on geosynthetics, Bologna, Italy, pp 403-406

13. Rail Network (2005) Network rail specification; NR/SP/TRK/ 9039-formation treatment. Network Rail, London

14. Perkins SW (1999) Geosynthetic reinforcement of flexible pavements: laboratory based pavement test sections. Federal Highway Administration Report No. FHWA/MT-99-001/81838

15. Raymond GP (1984) Track support must be right if concrete sleepers are to survive. Railw Gazette Int 140(7):528-530

16. Sharpe P, Brough M, Dixon J (2006) Geogrid trials at Coppull Moor on the West Coast Main Line. In: Proceedings, railway foundations. University of Birmingham, UK, pp 367-378

17. Shin EC, Kim DH, Das BM, Lee ES (2001) Stress distribution in reclaimed land under a geogrid-reinforced granular pad. In: Proceedings of XI international conference of offshore and polar engineering, Stavanger, Norway, pp 675-680

18. Tensar International (2000) Ground stabilization - rail track Nagykanizsa, Hungary. Tensar Case Study, Ref. 058. Tensar International Limited, Blackburn, $2 \mathrm{p}$

19. Thom NH (2009) Rail traffic testing. In: Jubilee symposium on polymer geogrid reinforcement. Institute of Civil Engineers, London, England, pp 61-66

20. U.S. Army Corps of Engineers (2003) Use of geogrids in pavement construction. ETL 1110-1-189

21. U.S. Department of Transportation. Federal Highway Administration (1994). Geogrid reinforced base course. Engineering Brief No. 49

22. Walls JC, Galbreath LL (1987) Railroad ballast reinforcement using geogrids. In: Proceedings of geosynthetics '87, New Orleans, Louisiana, USA, pp 38-45 